\title{
Ensino de Ciências da Terra a partir da cidade
}

\author{
EaRTH SCIENCES TeaChING FROM THe CITY
}

Pedro Wagner Gonçalves ${ }^{1}$, Natalina Aparecida Laguna Sicca ${ }^{2}$, Maurílio Antonio Ribeiro Alves ${ }^{2}$, Celso Dal Ré Carneiro ${ }^{1}$, Carlos Alberto Lobão da Silveira

Cunha ${ }^{1}$, Oscar Braz Mendonza Negrão ${ }^{1}$

1 - Universidade Estadual de Campinas, Instituto de Geociências

2 - Universidade de São Paulo, FFCL de Ribeirão Preto (aposentado-a)

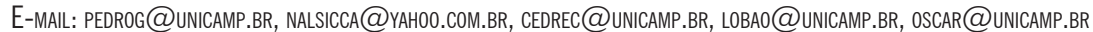

Abstract: Former studies on the renew curricula and programs on Earth Sciences those which were elaborated in the 1960's and 70's examined different problems and questions, such as political motivations, cultural dependency from main capitalistic countries, excessive theoretical point of view etc. This study examines an important idea: the relationship between process and product to teach geological concepts and explanations. The construction of educational objectives using a set of verbs, as follows: to observe, to infer, to describe, to define, to apply, to classify, to predict, to interpret (such as to distinguish from evidence and proof) is inextricably linked to the valuation of the process. The advancement of learning and of other fields of knowledge brings out the idea of elaborating a subject matter for teaching from the city and town questions. These elements help to promote a context for learning as well as they facilitate field trips.

\section{Manuscrito:}

Recebido: Artigo selecionado, IX Simpósio Nacional de Ensino e História de Ciências da Terra / EnsinoGE0-2019

Aceito: 07/10/2019

Citação: Gonçalves, P. W.; Sicca, N. A. L.; Alves, M. A. R. ; Carneiro, C. D. R; Cunha, C. A. L. S; Negrão, 0. B. M. (2019). Ensino de Ciências da Terra a partir da cidade. Terræ Didatica, 15 , 1-8, e19049. doi: 10.20396/td.v15i0.8657609

Palavras-chave: Ensino de Geociências, História do Ensino de Ciências, Didática das Ciências.

\section{Introdução}

Em 1994, o primeiro autor (PWG) examinou o desenvolvimento da disciplina de Geologia Introdutória (GI) do Instituto de Geociências da Universidade Estadual de Campinas (Gonçalves, 1994). Na época usamos uma referência chave: o trabalho pioneiro de Amaral (1981a) que mostrou as marcas de conteúdo e didática da GI desenvolvida na Universidade de São Paulo entre 1973 e 77. "A Geologia Introdutória na universidade - análise de um modelo de curso" descreveu o programa destinado a introduzir alunos do nível superior, bem como seus propósitos. A retomada de 1994 comparou permanências e avanços entre os dois momentos mencionados.

Neste momento, retomamos a preocupação que orientou esses dois trabalhos anteriores e pretendemos fazer um balanço de pesquisas e experiências sucessivamente realizadas nesses mais de 40 anos para renovar o Ensino de Ciências da Terra, bem como reforçar a história das mudanças educacionais ocorridas e construir um quadro comparativo de semelhanças e diferenças dos esforços iniciais e os passos que foram dados ao longo do tempo.

A renovação do Ensino de Ciências da Terra no Brasil está marcada pela adaptação do livro curso Investigando a Terra (original norte-americano elaborado pelo Earth Science Curriculum Project, na década de 1960, dentro do movimento de reformulação de currículos e programas de Ciências, ESCP, 1978).

A adaptação brasileira feita no âmbito da colaboração e ajuda promovidos por órgãos bilaterais dos EUA (Agência dos Estados Unidos para o Desenvolvimento Internacional mais conhecida por sua sigla em inglês, USAID). A partir da década de 1950 e sobretudo depois da Revolução Cubana voltou-se para promover o desenvolvimento social e cultural da América Latina. Os acordos entre o Ministério da Educação do Brasil e a USAID 
foram estreitados em um momento especialmente sombrio da história brasileira (durante a ditadura civil militar iniciada em 1964). Apesar disso, a reorganização e ampliação do escopo do conteúdo; a valorização dos procedimentos metodológicos de elaboração do conhecimento e o ensino centrado no aluno abriram um caminho para refletir e pesquisar os problemas de ensino e da aprendizagem relativos ao planeta Terra.

A renovação do ensino de Ciências da Terra, da década de 1960, promovida por um conjunto de iniciativas e interações de distintos países (principalmente EUA, Inglaterra, Israel) foi conduzida por eixos curriculares que simplificadamente poderíamos examinar sob o enfoque das questões da natureza da ciência e dos desafios didáticos para promover a aprendizagem. A História e Filosofia da Ciência e a Didática das Ciências podem ajudar a aclarar potencialidades e limites dessas iniciativas de 50 anos atrás. O objetivo deste trabalho é mostrar que um desses eixos (a relação processo e produto) a um só tempo caracteriza um aspecto chave daquele momento da história do ensino de ciências, bem como como foi superado ao privilegiar o estudo da cidade e do local.

\section{Processo e produto para organizar a metodologia de pesquisa das Ciências da Terra}

Uma questão que serviu de eixo para o debate de currículos e programas de Ciências da Terra na década de 1960 foi como privilegiar o processo diante do produto da ciência, ou seja, processo e produto foram tratados como partes de binômio que pretendia privilegiar um dos polos considerado muito menor pelo ensino tradicional. Anguita (1996) mostrou como foi feita a introdução do termo Geociências no Ensino de Geologia: naquele período, meados da década de 1970, surgiram livros de texto de autores como Arthur Newell Strahler que trouxeram a terminologia nova e, ao mesmo tempo, ampliaram o escopo do Ensino de Geologia: incorporaram os campos relativos à atmosfera, à hidrosfera e ao espaço extraterrestre ao lado da esfera tradicional, a crosta terrestre. Aproximadamente na mesma época, os programas e currículos renovadores (oriundos principalmente dos EUA, Inglaterra e Israel) introduziram uma série de ideias didáticas que almejavam envolver o aluno no processo de descoberta dos princípios e estrutura do conhecimento geológico (como é exemplifica- do pelo ESCP, 1978, cujo título em português é: Investigando a Terra).

O movimento de renovação educacional de ciências reagia ao que se considerava um ensino enciclopédico e compartimentado. No chamado ensino tradicional, os assuntos e tópicos eram tratados como produtos do conhecimento e, ao mesmo tempo, encobriam os processos e fazeres relativos às descobertas. Isso sugeria um ensino livresco, verbal e enfadonho que afastava os alunos e inibia a vocação para a pesquisa e atividades científicas e tecnológicas. Amaral (1981b) identificou que o conhecimento veiculado pelos livros textos de Geologia Introdutória usados nas universidades brasileiras privilegiavam os produtos do conhecimento. Este autor comparou a presença e a importância do binômio processo e produto como polos para abordar todos os temas do livro texto. Dessa maneira, em uma amostra de 40 livros texto, houve predomínio do polo produto na maioria das obras examinadas. Apesar disso, no Investigando a Terra houve um equilíbrio entre os dois polos.

Tais elementos ajudam a montar um quadro preliminar, mas suficiente para identificar a preocupação dos renovadores com os processos naturais e sua descoberta. Para eles, isso se constitui como eixo curricular que marcou a renovação do Ensino de Ciências da Terra daquela época.

No presente trabalho mostramos como e porque a valorização de processo foi modificada a medida que a ideia de Ciência do Sistema Terra tornou-se mais comum e novos elementos passaram a valorizar a cidade e o local como alvos educacionais.

\section{Contexto cultural da renovação de currículos e programas de Ensino de Ciências da Terra nos anos 1960}

O movimento educacional de mudança do Ensino das Ciências da Terra fez parte de um esforço de mudanças do Ensino de Ciências Naturais, Experimentais e Matemática. As características básicas das mudanças foram descritas por Matthews (1994). Em termos algo simplificados, corresponderam à valorização dos princípios e da estrutura das distintas disciplinas científicas que eram parte da formação de crianças e jovens (p.ex., Biologia, Física etc.). Em outros termos, significou implementar uma política de currículos disciplinares (o termo currículo disciplinar diz respeito ao estilo de currículo e se opõe ao currículo interdisciplinar na 
tipologia de Lopes \& Macedo, 2002). Em todas as áreas foi valorizada a experimentação como etapa capaz de conduzir os alunos a compreender leis e princípios das ciências. Largamente se pretendia despertar a vocação científica e, dessa forma, aumentar o número de profissionais ligados às ciências e à tecnologia.

Para Bruner (1961) a aprendizagem por descoberta era um modo dos estudantes compreenderem a natureza da pesquisa científica. Os alunos aprenderiam por si mesmos sobre a natureza da descoberta e o pensamento científico. Matthews (1994) mostra que isso implicou rever e reformular o que deveria ser ensinado aos estudantes. Novos programas, materiais didáticos e propostas para formação de professores foram desenvolvidos para melhorar a Educação em Ciências.

Amaral (2014) mostrou que no caso do Investigando a Terra houve maior integração entre teoria (conceitos e explicações) e prática (atividades de observação e experimentação) do que em campos, tais como, Física e Química.

A valorização das atividades práticas com caráter educacional pretendia mostrar qual é a metodologia da pesquisa científica e difundir a noção da ciência como atividade de pesquisa (no caso do ESCP, 1978, trata-se de um eixo curricular explícito). Em qualquer uma das disciplinas envolvidas, há um esforço para mostrar as diferenças entre observar, inferir, interpretar e prever. Por outro lado, a maioria dos programas negligenciou aplicações práticas e técnicas da ciência.

No tratamento dos temas de Ciências da Terra isso se integra ao valor atribuído ao processo diante dos produtos do conhecimento. Tomando como exemplo o ESCP (1978), vamos encontrar um amplo conjunto de "atividades práticas" nas quais há privilégio do processo na construção do conhecimento. Usamos, aqui, a ideia de atividade prática de Bonito (2001): quaisquer atividades que envolvam manipulação de materiais (o que inclui laboratório) e atividades extra muros.

O ESCP (1978) desafia os alunos a reconhecer as etapas básicas da construção do conhecimento científico das ciências históricas: observar, interpretar, inferir e prever acontecimentos que ocorreram no passado (retrodição, ou explicação sobre o que ocorreu no passado a partir de evidências do presente). Um caso excepcionalmente bom para refletir sobre os elos das tarefas postas às pesquisas das Ciências da Terra e especialmente da Geologia está vinculado ao tema "universalidade da transfor- mação": a partir de duas fotos aéreas de uma duna barcana obtidas com um intervalo de 7 anos entre uma e outra, os estudantes são convidados a descobrir qual é a foto é mais antiga. A atividade permite passar pelos elementos constitutivos do raciocínio geológico: observar e interpretar representações visuais sobre um fenômeno (com a simulação do que se observa no campo a partir do signo icônico do fenômeno), formulação de hipótese apoiada em evidências, construção de uma explicação histórica para inferir e prever o que aconteceu, perceber a partir da controvérsia (diferentes explicações possíveis diante de um mesmo fenômeno e conjunto de evidências) que o conhecimento científico é provisório e situado historicamente, ou seja, perceber que a ciência é uma elaboração resultante da pesquisa.

A atividade das dunas está relacionada à pergunta: como os geólogos interpretam registros e formas fixadas para narrar uma história do passado? A pergunta abrange, ainda, o esforço de descrição qualitativo dos fluxos de energia e matéria de processo ocorrido no passado a partir de produtos observados nas fotos, ou seja, a um só tempo há uma discussão metodológica sobre coleta de evidências, sua interpretação (trata-se de uma abordagem sistêmica) e dessa forma o assunto é o processo e não o estado fixado das dunas nas fotos (um dos modos de expressar a universalidade de transformação).

Narrar a estória das dunas é um processo que engaja os estudantes para refletir de modo dominantemente indutivo. A clareza sobre essa ênfase conduziu a combinar o estudo das dunas a um pequeno trecho do romance "O nome da rosa" de Umberto Eco visando demonstrar que os significados atribuídos às formas fixadas dependem de uma combinação sistêmica de raciocínios nos quais a indução se combina à abdução para dar totalidade que torna possível combinar e articular as evidências. Ao mesmo tempo, tal síntese de informação requer uma explicação global (o que pode ser chamado de programa de pesquisa usando a linguagem de Lakatos ou paradigma sob o enfoque tradicional de Kuhn, ver Lakatos \& Musgrave, 1979).

Todos esses elementos avançam e aprofundam a ideia disciplinar que caracteriza os estudos geológicos. Largamente o caráter histórico adquire especial interesse e destaque, mas é necessário se perguntar: um geólogo caracteriza os fluxos, processos e transformações do passado em separado de um problema que precisa ser resolvido? Todos os 
raciocínios são empregados "em geral” ou, servem para identificar e descrever uma jazida mineral, diagnosticar um risco de acidente ambiental, prever os futuros problemas da destinação de resíduos urbanos de uma cidade etc.? Ou seja, estudos geológicos são contextualizados por problemas que precisam ser enfrentados, eles aconteceram em certo lugar. Mesmo quando se quer descrever o movimento de uma duna do passado, isso ocorre em torno de perguntas sobre colonização vegetal da duna, velocidade do vento no local, época geológica em que ocorreu etc. - todos os elementos que caracterizam a pesquisa geológica remetem a contextualizar o local.

Em outros termos, as histórias precisam ter um significado. É evidente que compreender a história da duna promove uma aprendizagem ativa que muitas vezes é centrada no aluno. Mas não se pode perder de vista que tal ênfase no processo (com dois sentidos: processo de pesquisa e de aprendizagem) constrói uma história descarnada, pois as histórias geológicas adquirem forma e sentido quando tratam de um problema específico (diagnóstico de uma enchente, ampliação de uma jazida de ferro etc.).

Ao fazer a atividade das dunas, o estudante adquire experiência de observar e interpretar um fenômeno a partir de evidências, pergunta-se sobre fontes de energia e de movimento. Adquire, enfim, habilidades e competências de pesquisa que ajudam a conduzir a ideia de ciência como pesquisa. Por outro lado, falta ter um significado que ajude a incorporar tais conhecimentos à sua vida. É justamente esse significado que se acha vinculado à atividade voltada para a cidade e o local. O significado das transformações da natureza requer um caráter genuíno que é atribuído pelo contexto.

Em trabalho anterior, Gonçalves \& Sicca (2018) mostraram que a literatura que organiza os vínculos entre local e Ensino de Ciências da Terra faz uma aproximação com os problemas multiculturais (Semken et al., 2009; Semken et al., 2017; McDaris et al., 2017; Kirkby, 2014; Cohn, 2014; Apple, Lemus \& Semken, 2014). Mas há uma abordagem diferente, feita por Ault (2014), que se afasta das justificativas multiculturais; para ele, o Ensino de Ciências promove até hoje a padronização e abordagens descontextualizadas. Ault (2014) defende a aprendizagem baseada no lugar porque isso permite um tratamento contextualizado dos conceitos científicos, revela vínculos mais claros com a pesquisa geológica e trata problemas particulares que possi- bilitam tratamentos e reflexões multidisciplinares. As Ciências da Terra permitem a aprendizagem que combina o pensar e o fazer; este é um caminho que adapta o contexto aos propósitos do ensino. O mesmo autor complementa: métodos de investigação e de conceituação tornam-se mutuamente dependentes para explicar eventos e objetos particulares (possibilitando entender a existência de vários tipos de ciências, distintas abordagens metrológicas como é o caso dos estudos da Salina de Bebedero e da Eletrometalúrgica Brasileira - o que será mais bem desenvolvido ao longo deste texto). Ault (2014) assinala, ainda, que o conhecimento do lugar modifica a vida dos cidadãos (o normal e ordinário torna-se extraordinário e fonte de conhecimento), de outro lado, um conhecimento descontextualizado do lugar aspira a uma universalidade que se afasta da vida das pessoas.

Pôr o foco do Ensino de Ciências da Terra em torno do problema metodológico como é exemplificado pela história das dunas, não responde ao ponto crucial: o que ensinar? É necessário ter um ponto de partida que não se justifica pela pesquisa científica, mas é crucial do ponto de vista ético: as Ciências devem contribuir para formar cidadãos. Muitas respostas têm sido dadas, mas aceitar o conceito de alfabetização em Ciência do Sistema Terra (base da alfabetização ambiental) contempla diferentes formulações que delimitam unidades a ser tratadas como um mínimo capaz de contemplar o que um cidadão deve dominar em termos de conceitos e capacidade instrumental de usá-los na sociedade do conhecimento.

\section{Principais críticas ao movimento de renovação de currículos e programas de Ciências da década de 1960}

Uma primeira crítica é quanto ao caráter dos programas e currículos patrocinados pelo National Science Foundation (NSF): quais eram seus propósitos mais amplos e o que tentavam alcançar em termos do padrão de desenvolvimento econômico, político e social. Eles visavam superar a corrida armamentista e especialmente o atraso do programa espacial dos EUA depois do lançamento bem sucedido do Sputinik (1957) e do primeiro cosmonauta posto em órbita da Terra: Iuri Gagarin (1961). A resposta norte-americana foi um programa de financiamento para melhorar o ensino de Ciências Naturais, Experimentais e Matemática destinado a formar uma nova geração de pesquisadores para 
promover o progresso das ciências.

Matthews (1994) conta que o National Defense Education Act (1957) liberou US\$ 94 milhões para o ensino de ciências de 1958 a 61 e outros 600 milhões de 1961 a 75 . Reuniões e conferências ocorreram em todo o território dos EUA para melhorar o ensino e preparar os estudantes para a atividade científica.

A Revolução Cubana que culminou com a deposição de Fugêncio Batista em 1959 foi um choque para a diplomacia e política internacional dos EUA principalmente em relação aos países latino-americanos. Durante a década de 1950, houve vários acordos firmados entre os governos do Brasil e dos EUA para promover a cooperação cultural entre os dois países. Apesar do significado histórico destes, a assessoria para planejar particularmente o ensino superior foi atingida por acordos assinados entre 1965 e 67 que marcaram a colaboração técnica Brasil-Estados Unidos no âmbito da educação (conhecidos por sua sigla Acordos MEC-USAID). Dentre os acordos, houve a transferência dos programas de Ensino de Ciências e Matemática que alcançaram as escolas brasileiras a partir do final da década de 1960, abrangendo tradução e adaptação de materiais didáticos para o ensino de Biologia, Física, Matemática, Química e Ciências da Terra, analogamente ao que acontecera em outros países, como, p.ex., México e Venezuela.

Mas além da crítica política e ideológica, o movimento de renovação educacional foi acompanhado por um processo de avaliação. Um primeiro aspecto que chamou a atenção dos avaliadores é a enorme diferença temática entre os programas renovados e os tradicionais que haviam sido aplicados durante décadas nos EUA.

Matthews (1994) mostra que uma tendência importante do desenvolvimento da Educação em Ciências, na década de 1950, foi reconhecer os aspectos práticos, vocacionais, sociais e humanitários da ciência e incluir tais aspectos no currículo. Em resposta a múltiplas demandas, a Biologia escolar tornou-se mais "prática, ecológica, econômica, relativa ao bem estar humano": negócios e indústria, problemas ambientais, mudanças demográficas, questões de saúde; esse é um exemplo, mas revela como mudou o ensino de "Biologia para Biologia" e passou a tratar do bem estar humano. Consequentemente houve um choque diante dos programas e currículos da década de 1960 porque abandonaram radicalmente a perspectiva prática e tecnológica e adotaram a ideia de "ciência como pesquisa": uma busca pelo avanço do conhecimento em si.

Matthews (1994) explora, ainda, as tendências do Ensino de Ciências norte-americano durante o século XX: (a) uma primeira, que marcou as décadas de 1960 e 70, que foi teórica e reforçou a estrutura das disciplinas; (b) outra foi aplicada e reforçou a ciência e os trabalhos relativos ao cotidiano; (c) e a terceira, liberal ou contextual, reforçando o desenvolvimento histórico e as implicações culturais da ciência.

O caráter fortemente teórico e disciplinar, separado do cotidiano e dos campos aplicados do conhecimento científico foi fortemente criticado.

Robinson (1998) fez críticas mais específicas e assinalou o pouco valor atribuído à História da Ciência nos programas renovadores do Ensino de Ciências. Na segunda metade da década de 1970, uma outra fonte de críticas foi a falta de nexos entre os conceitos e os aspectos aplicados e tecnológicos. Esta acabou perseguindo duas ideias chaves que se combinaram: a perspectiva de ciência, tecnologia e sociedade e a de alfabetização científica. Embora, na década de 1990, tenha se tornado mais comum a ideia de associar Ciência para todos e alfabetização científica, de fato, desde a década de 1950 o problema já havia sido levantado (Hurd, 1958).

O que precisamos assinalar é o nítido conflito de propósitos entre um ensino voltado para despertar vocações e outro universal voltado para formar a cidadania. Os programas renovadores veicularam a ideia de uma ciência neutra e desvinculada dos problemas tecnológicos, econômicos e sociais.

Passado o período inicial de julgamento da década de 1970, uma enorme quantidade de críticas foi levantada à perspectiva de ciência e de ensino imbricada aos projetos de renovação de currículos e programas. O número de questionamentos e de autores é muito grande, o que largamente vai muito além de nossos propósitos nesta pesquisa. Nos limites deste texto, correndo o risco de simplificar excessivamente o problema, alinhamos alguns aspectos: crianças e estudantes não são pesquisadores profissionais, portanto aprender pelo método da descoberta cria uma falsa ideia de neutralidade e confiança excessiva no método para resolver problemas.

A pesquisa científica tem inúmeras peculiaridades em termos de formação dos pesquisadores; do seu treinamento para usar meios e instrumentos técnicos, bem como conceituais e culturais. As descobertas têm sentido dentro de uma comunidade

\begin{tabular}{c|c|c|c|c|c}
\hline (C) Terrae Didat. & Campinas, SP & v.15 & $1-13$ & $\mathrm{e} 0190 \mathrm{xx}$ & 2019 \\
\hline
\end{tabular}


que promove e valida seus resultados. Nenhum elemento disso está posto para o contexto escolar e, portanto, os desafios dos alunos são diferentes e não podem ser comparados aos do conhecimento científico.

Em termos resumidos, a aceitação das análises da História, Filosofia e Sociologia da Ciência revelam intricados mecanismos que interferem desde a observação, modos de conduzir a inferência e fazer as previsões que não existem no contexto escolar e, portanto, aspectos básicos dos procedimentos e atividades propostos nos currículos e programas renovados da década de 1960 podem ajudar a compreender o abandono daqueles materiais e da estrutura do ensino preconizado naquela época.

\section{Dinâmica da aprendizagem e objetos de ensino que emergem da cidade}

Nos dias atuais, há outro conjunto de elementos que é mais fácil ser percebido e que não fez parte das críticas das décadas de 1970 a 90: o estágio de desenvolvimento do conhecimento científico da aprendizagem. As críticas feitas ao longo do tempo podem ser agrupadas no que modernamente chamamos natureza da ciência. Muitos limites dos currículos e programas de renovação do Ensino de Ciências da Terra revelam as restrições das concepções da própria ciência, de sua história e dos modos como evidências e explicações se interconectam.

Só isso já seria suficiente para mostrar os limites de valorizar apenas o processo no desenvolvimento do ensino. Ou seja, há elementos atuais que ultrapassam um aspecto que foi considerado central na década de 1960: o privilégio do processo diante do produto.

A renovação do ensino foi apoiada, de um lado, em uma psicologia cognitiva cujas fontes principais eram o comportamentalismo e o construtivismo piagetiano. A outra fonte importante foi a própria disciplina científica com seus conceitos e organização. A década de 1990 pôs à disposição da Educação em Ciências um enorme âmbito de pesquisas psicológicas e de estudos dos vínculos da psicologia cognitiva e a linguagem, bem como seus nexos com a neurociência. Em conjunto, isso alterou o modo de pensar as relações que são positivas para promover a aprendizagem, além de deixar mais claro o papel do professor na aprendizagem dos estudantes, e o papel dos tratamentos relacionais de conceitos e vida cotidiana. Extrapola muito a finalidade deste texto explorar todas as conexões, mas é importante assinalar que acompanharam os avanços em outro campo: as Ciências da Terra. Avanços do sensoriamento remoto, Tectônica de Placas, Geologia Planetária e desafios ambientais (explosão demográfica, perda da diversidade biológica, mudança climática global etc.) permitiram emergir o campo de estudo da Ciência do Sistema Terra, bem como o seu ensino.

A combinação desses elementos conduziu à valorização dos estudos da cidade como ponto de partida para compreender o funcionamento do planeta e do ambiente. Dois passos interligados que promovem a alfabetização em Ciência do Sistema Terra e a alfabetização ambiental.

Essa visão integrada do planeta e o domínio dos raciocínios para tratar a complexidade terrestre é parte componente da cidadania em um momento de desafios científicos e tecnológicos. Portanto, a abordagem de estudos da Terra é um direito, ou seja, é necessário em todos os níveis básicos da educação e da formação de professores. Marca importante desse ensino é partir dos problemas da cidade: ou seja, ao invés de permanecer no estudo dos mecanismos de transformação da natureza, interligá-los aos problemas locais: o ciclo da água tratado a partir das enchentes e matas urbanas; o ciclo da areia tratado de acordo com a necessidade de materiais de construção; a mudança climática tratada por meio das transformações da Salina de Bebedero (Argentina).

Seja do ponto de vista dos estudos da Filosofia da Ciência, seja nas reflexões sobre do Ensino de Ciências, embora não haja consenso em nenhum desses campos sobre as diferenças entre as ciências, podemos identificar certo alinhamento em torno da ideia de que as ciências naturais e experimentais podem ser dominantemente experimentais e analíticas. Suas explicações conduzem a leis universais; de outro lado, há campos cujo estudo da singularidade e da configuração remete a construir explicações históricas. Ora, o Ensino de Ciências deve fornecer aos estudantes os elementos necessários para compreender os dois modos de investigar a natureza e gerar conhecimentos capazes de ajudar a compreender de modo racional o mundo à nossa volta (esses aspectos são mais bem desenvolvidos por: Ault \& Dodick, 2010 e Dodick, Argamon \& Chase, 2009). Isso sugere que a alfabetização em Ciência do Sistema Terra é componente da alfabetização científica e indica um modo muito particular de tratar outro tema estratégico do Ensino de 
Ciências que é a natureza da ciência.

Trazer a História e a Filosofia da Ciência como marcos orientadores da alfabetização científica requer, de um lado, o equilíbrio desses campos e implica mostrar a história das explicações experimentais e históricas. A diversidade das ciências transposta para o ensino implica tratar dos dois espaços e de seus papéis relativos: ciências experimentais têm o laboratório como espaço privilegiado de produção de conhecimento; de outro lado, ciências históricas valorizam o espaço do campo como fonte de informação (observação direta da natureza).

Quando o Ensino de Ciências é tratado sob o foco da natureza da ciência corresponde ao reconhecimento da diversidade dos campos científicos e fornece uma indicação prescritiva da necessidade de incorporar Ciências da Terra como contributo à formação do pensamento sistêmico e histórico.

Vejamos um exemplo. Há uma diferença substancial entre explorar a história da Salina de Bebedero que serve como contraponto à história das dunas. Bebedero é tratada como fato único seja do ponto de vista natural, seja do ponto de vista social. Explorar o que acontece em Bebedero (responder as três questões: por que a lagoa está secando? por que há uma lagoa em Bebedero? de onde vem o sal?) não apenas conduz a compreender relações sistêmicas e a história geológica recente, mas depende de identificar evidências, fazer comparações, classificar dados.

\section{Conclusões}

Ao comparar o ensino de Ciências da Terra em um intervalo de tempo, percebemos que há permanência de atividades que valorizam o processo em relação ao produto, sobretudo nos contextos escolares voltados para estudantes da universidade e formação de professores em grupos de formação continuada. Entretanto, um olhar minucioso sobre as marcas do Ensino de Ciências da Terra voltadas para a formação básica de crianças, adolescentes e jovens, bem como para formação inicial e continuada de professores revela a permanência de alvos educacionais acompanhada da crescente valorização da cidade como objeto de ensino.

Muitos argumentos favoráveis poderiam ser alinhados à opção por tratar a cidade; nos limites desta discussão privilegiamos o papel do contexto como aspecto importante de elaboração de raciocínios sistêmicos e complexos para compreender a Terra e o ambiente.
O exame do ESCP (1978) mostra a marcante importância do processo diante do produto por meio de atividades práticas usadas independentemente do objeto de estudo. Trata-se de um caráter metodológico profundo de valorização disciplinar cujo alcance mais amplo conduz à perspectiva de verdadeira metodologia de pesquisa aplicável a praticamente todas as ciências empíricas, embora na sua constituição dê uma contribuição particular para construir a ciência histórica. Em outros termos, é um modo de reforçar no ensino e na aprendizagem um tópico que foi central naquele período: o equilíbrio do binômio processo e produto.

Os avanços propiciados pela abordagem da Ciência do Sistema Terra valorizam o estudo dos conceitos e explicações a partir da cidade. Os exemplos da abordagem são os estudos da Salina de Bebedero (mudança climática global), Eletrometalúrgica Brasileira de Ribeirão Preto (transformações do ferro na crosta terrestre do Arqueano ao presente), enchentes em Ribeirão Preto (ciclo da água), abastecimento de água em Ribeirão Preto (estudos da capacidade, potencialidade, vulnerabilidade do Aquífero Guarani - vinculado à origem geológica) etc.

O privilégio do ensino apoiado no processo alcança ponto central da Didática das Ciências no auge dos programas de renovação educacional da década de 1960. Acha-se imbricado com a concepção de ciência e com o ensino centrado no aluno (crucial para a descoberta dos princípios fundamentais dos estudos da Terra). Pôr a cidade como alvo educacional significa contextualizar o ensino a partir do lugar, facilita as atividades de campo, permite valorizar a linguagem visual por meio de vídeos e fotos. O deslocamento do foco do Ensino de Ciências da Terra pode ser explicado pelo resultado combinado da reflexão sobre a prática e o esforço de se aproximar dos avanços teóricos do ensino e da aprendizagem.

\section{Agradecimentos}

Agradecimentos são devidos a estudantes e professores que participaram das atividades que promovemos ao longo dos anos para ensinar Ciências da Terra.

\section{Referências}

Amaral, I. A. do. (1981). A Geologia Introdutória na universidade: análise de um modelo de curso. In: Simpósio Nacional de Ensino de Geologia no Brasil, 1, 1981,

\begin{tabular}{c|c|c|c|c|c}
\hline (C) Terrae Didat. & Campinas, SP & v.15 & $1-13$ & $\mathrm{e} 0190 \mathrm{xx}$ & 2019 \\
\hline
\end{tabular}


Belo Horizonte. Teses. Belo Horizonte: Sociedade Brasileira de Geologia, v.1, p.45-56.

Amaral, I. A. do. (1981b). O conteúdo e o enfoque do livros de Geologia Introdutória: estudo descritivo e analítico com base na macro-estrutura das obras atuais destinadas ao nível superior de ensino. São Paulo: Universidade de São Paulo. Dissertação de Mestrado. Geociências.

Amaral, I. A. do. (2014). Ensino de geologia introdutória: raízes e desdobramentos da mudança curricular em 1973 na USP. Terre Didatica, 15(3), 161-170.

Anguita, F. (1996). Geología y ciencias de la Tierra: etimología y un poco de historia. Enseñanza de las Ciencias de la Tierra, 4(3), 177-180.

Ault Jr., C. R.; \& Dodick, J. (2010). Tracking the Footprints Puzzle: The Problematic Persistence of science-as-Process in Teaching the Nature and Culture of Science. Science Education, 94(6), 1092-1122.

Bonito, J. (2001). As actividades práticas no ensino das Geociências: um estudo que procura a conceptualização. Lisboa: Instituto de Inovação Educacional. 290p.

Bruner, J. S. 1961. The act of discovery. Harvard Educational Review, 31, 21-32.
Earth Science Curriculum Project (ESCP). (1978). Investigando a Terra: guia do professor. São Paulo: McGraw-Hill. 2v.

Dodick, J.; Argamon, S.; \& Chase, P. (2009). Understanding Scientific Methodology in the Historical and Experimental Sciences via Language Analysis. Science E Education, 18, 985-1004.

Goncalves, P. W. (1994). A Geologia Introdutória na Universidade: Análise de um modelo de curso. Campinas, Cadernos do IG/Unicamp, 4(2), 90-116.

Hurd, P. De H. (1958). Science literacy: its meaning for American schools. Educational Leadership, 16(1), 13-16.

Lopes, A. C.; \& Macedo, E. (Orgs.). (2002). Disciplinase integração curricular: história e políticas. Rio de Janeiro, RJ: DP\&A. 220p.

Matthews, M. R. 1994. Science teaching: the role of history and philosophy of science. New York: Routledge. $287 \mathrm{p}$.

Robinson, J. T. (1998). Science teaching and nature of science: orig. 1965. Science \& Education, 7(6), 617634. 